\title{
Level of Depression in Tuberculosis Patients of Los Olivos Health Centers
}

\author{
Katherine Trinidad-Carrillo ${ }^{1}$, Ruth Santana-Cercado ${ }^{2}$ \\ Katherine Castillo-Ñañez ${ }^{3}$, Hernan Matta-Solis ${ }^{5}$ \\ Faculty of Health Sciences, Universidad de Ciencias y \\ Humanidades \\ Lima, Perú
}

\author{
Brian Meneses-Claudio ${ }^{4}$ \\ Image Processing Research Laboratory (INTI-Lab) \\ Universidad de Ciencias y \\ Humanidades \\ Lima, Perú
}

\begin{abstract}
Tuberculosis is a contagious infectious disease, caused by Mycobacterium Tuberculosis, transmitted through its release into the air when a sick person coughs, sneezes or talks, so it can be inhaled by another person and infect it, it is necessary for patients to adopt family, work and social distancing to avoid infections, causing a risk of developing different levels of depression, which is detrimental due to its negative influence on decision-making. The frequency of depression in society is high, as is the predisposition of patients diagnosed with Tuberculosis due to the sudden change in their lifestyle, which is why it was proposed to determine the level of depression in tuberculosis patients at health centers from Los Olivos district, this study will also allow to know the most frequent physical and psychological reactions, in addition to the most predominant sex. To obtain the information, the corresponding permits were obtained and the Patient Health Questionnaire 9 (PHQ-9), an international and nationally validated standardized instrument, was applied; the data was processed in the statistical software SPSS 24.0, and the graphics were subsequently extracted; where the following obtained results were reflected: $100 \%$ of the participants had some level of depression, the most prevalent being the level of moderate depression with $35.56 \%$, being more present in the female population with $21.11 \%$, it was also shown that $48.9 \%$ of patients almost always have little interest or pleasure in doing things.
\end{abstract}

Keywords-Tuberculosis; depression; patient health questionnaire 9; health centers; tuberculosis lifestyle

\section{INTRODUCTION}

Depression is a common and debilitating mental disorder (1), characterized by a feeling of sadness, loss of interest, guilt, low self-esteem, sleep or appetite disturbances, fatigue and lack of concentration (2), according to a report by the WHO and PAHO, a total of 322 million people who suffer from it, of which 1,443,513 belong to Peru and 9.7\% of them have some non-psychiatric illness (3). Affected people decrease the ability to carry out their daily activities and have low academic performance, affecting economically and socially, in addition has a negative influence on adherence to anti-tuberculosis treatment (4) causing treatment abandonment which generates an increase in resistant multidrug TBC rate (5).

Tuberculosis is an old disease, however, it continues to be a public health problem worldwide, causing around 1.7 million deaths and 9 million new cases each year $(6,7)$, and has also been shown to be fatal for patients with HIV-AIDS (8), it is known that the bacterium Mycobacterium tuberculosis, according to the WHO, this bacterium would be present in at least a third of the world population $(9,10)$, can lodge in different organs, however, the cases in which lodges in the lungs (11), these smear-positive patients are highly infectious, since they generate coughs, chants, screams, sneezes, nuclei of drops containing the bacteria (12) that can be inhaled by Healthy people, individual and environmental factors intervene in this process, such as: the person's lifestyle and the ventilation of the environment (13).

Patients diagnosed with Tuberculosis generally belong to poorer social strata (14), who have to make changes in their lifestyle, which can have psychological repercussions, the main one being depression, generally associated with social distancing $(4,15)$, which is closely related to the type of tuberculosis and its location.

Currently, many countries have a high burden of tuberculosis and are not on track to reach the goals set for 2020, this set seeks to end it, this as evidenced in the annual report of the World Health Organization, where they report that globally, the reduction targets set for infection and deaths are considerably lower (7).

The Instituto Nacional de Estadísticas e Informática, pointed out that $3.4 \%$ of people 15 years of age and older know or have heard of tuberculosis and recognize the forms of transmission, according to distribution by sex, the knowledge of transmission of the disease was higher in women $(4.1 \%)$ than in men (2.9\%), the majority of those who know about the form of transmission resided in metropolitan Lima, continuing, in lower percentages, the population of the coast and jungle, while in the Highland region, they showed that they did not know about different diseases, so better information is needed from the population (16).

In (4), the association of depression with the absence of patients in their treatment was evaluated, using the PHQ-9 depression scale as an instrument, where it was evidenced that depression was present in $76 \%$ of the population, In addition, a statistically significant association $(p>0.05)$ between levels of adherence and depression was determined, according to the instruments used.

In (17), the level of depression was evaluated in patients diagnosed with Tuberculosis, as a result they found that $54.5 \%$ 
of the study population had some level of depression. $32.7 \%$ of the patients had mild depression and $7.3 \%$ had severemoderate depression according to what was evaluated by the PHQ-9 depression scale, they also found a significant relationship according to sociodemographic data.

In (18), they evaluated the burden and presentation of depression in individuals newly diagnosed with Tuberculosis, obtaining as a result that the prevalence of depression was $54.0 \%$, where it was highlighted that little interest or pleasure in doing things $(73.0 \%)$ was the most common depressive symptom, they also determined that the duration and severity of Tuberculosis symptoms were important factors independently associated with depression.

In (19), the prevalence of depression in tuberculosis patients was $61.1 \%$; $38.9 \%$ of patients had no depression, $36.6 \%$ had mild depression, and $24.5 \%$ had moderate depression. Women were more affected than men (38.5\% vs. $22.6 \%$ ). Major depression was found in $41.5 \%$ of patients, with $27.9 \%$ of women and $13.6 \%$ of men.

According to the bibliographic search carried out for the preparation of this research, the scarcity of related studies was evidenced, as well as the age of the existing ones, therefore the main objective of the research work is to determine the level of depression in patients diagnosed with Tuberculosis who receive their treatment at the health centers of the Los Olivos district, Lima-Peru, it will also determine the most predominant factors of depression, the reactions physical and psychological, the importance of this research lies in the frequency of depression in society, in its consequences and in the predisposition to develop it in patients diagnosed with Tuberculosis due to the change in lifestyle.

The data will be obtained through the PHQ-9 questionnaire, which allows detecting Depression, from Mild to Severe, this has proven to be an efficient diagnostic instrument, in addition to being used nationally and internationally (20), however, it is not widely used in this population. Subsequently, the data will be processed using the SPSS Software, extracting the results from it to be interpreted.

The following research work is structured as follows: In Section II, the methodology for obtaining data and its processing will be presented, in addition to presenting the flow diagrams of the processes that were carried out to obtain the meaning of each image. In Section III, the results of the research work will be shown using bar graphs according to percentages. In Section IV, the discussions of the research work will be presented. Finally, in Section V, the conclusions on the research work as well as some recommendations on depression in tuberculosis patients will be presented.

\section{MethodOLOGY}

This section shows the procedures performed that consist of data acquisition and processing. As the reader can see the Fig. 1.

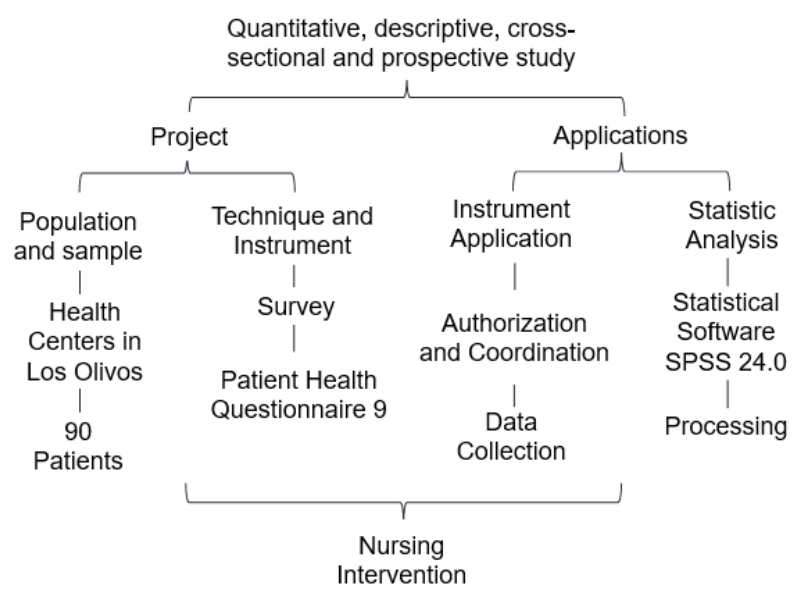

Fig. 1. Flow chart for Obtaining Results.

\section{A. Population and Sample}

For the research, the selected population were patients receiving treatment in the area of the national health strategy for the prevention and control of Tuberculosis in the health centers of Los Olivos district, Lima-Peru; the total of our sample was 90 patients who voluntarily participated in the study, being informed about the study and having an informed consent as evidence.

\section{B. Technique and Instrument}

As a data collection technique, the survey was used, which allowed to establish contact with patients; the instrument that was applied was the Patient Health Questionnaire 9 (PHQ-9), validated and submitted to the judgment of experts nationally and internationally for the screening for depression, through 9 items, in which patients rate their symptoms or signs on a Likert scale, the sum is distributed in: Minimum or none: 0-4, Mild: 5-9, Moderate: 10-14, Moderately severe: 15-19, Severe: 20-27 (21-24).

\section{Application of Instrument}

After the approval of the ethics committee of the Universidad de Ciencias y Humanidades, permission for the application of the instrument was requested from DIRIS (Direcciones de Redes Integradas) Lima - North.

Once the permission was obtained, data collection began in October 2019, mainly on Tuesdays and Wednesdays, on the recommendation of the managers of the area.

The instrument was applied individually and lasted approximately 15 minutes.

\section{Statistical Analysis}

The data was entered into a matrix table prepared in the statistical software SPSS 24.0, this process was carried out carefully to avoid errors and missing values at the time of analysis.

Finally, graphs and tables were extracted that will be described and then these will allow the discussion of the respective study. 


\section{E. Nursing Intervention}

The importance of the intervention of Nursing professionals lies in the interaction maintained during the collection of information, the trust and support provided during the completion of the survey to obtain real data as the reader can see in the Fig. 2. When the data is socialized, the nursing professionals who are in charge of the Tuberculosis control and prevention program will be able to approach and manage interventions to prevent depression in patients.

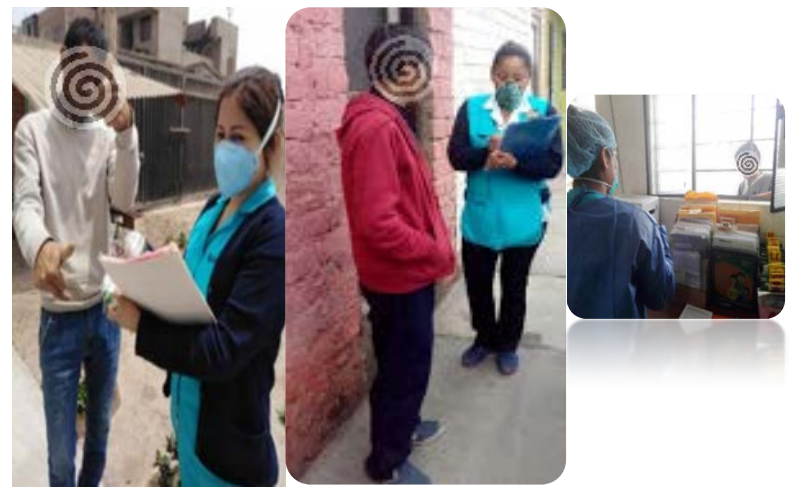

Fig. 2. Data Collection Procedure using the Survey.

\section{RESULTS}

The study included 90 patients who were receiving treatment for tuberculosis at the olive health centers.

The instrument allowed to synthesize as the reader can see in Fig. 3 the information collected, it shows that the level of moderate depression prevailed in patients with $35.56 \%$, followed by severe depression with $26.67 \%$, while $24.44 \%$ maintained a mild level of depression and $13.33 \%$ had a moderately severe level of depression, with no participants found without a level of depression.

Fig. 4 shows that of the total population, $60 \%$ belonged to the male, while $40 \%$ to the female. The predominant level of depression in the female was moderate with $21.11 \%$, followed by the severe level with $7.78 \%$, continuing with the moderately severe level with $6.67 \%$ and with a low level with $4.44 \%$.

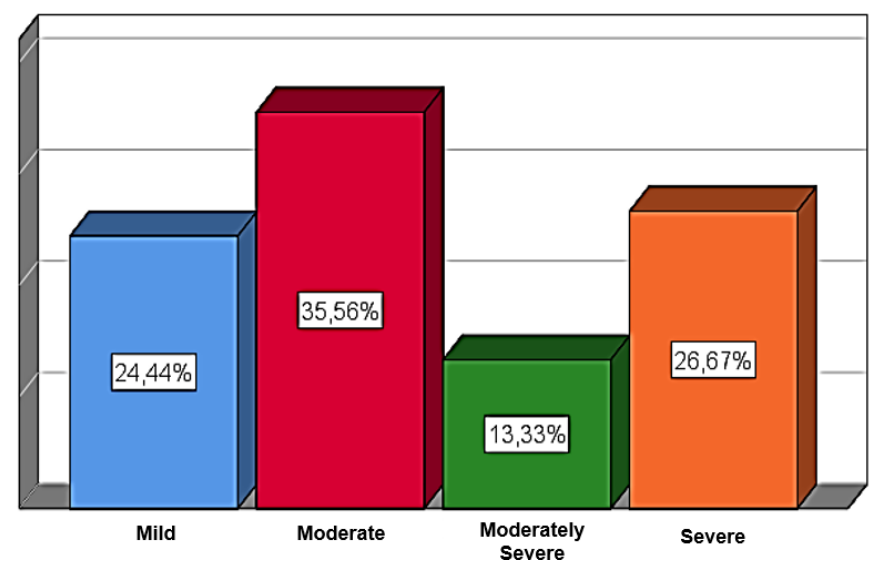

Fig. 3. Level of Depression in Patients with Tuberculosis.

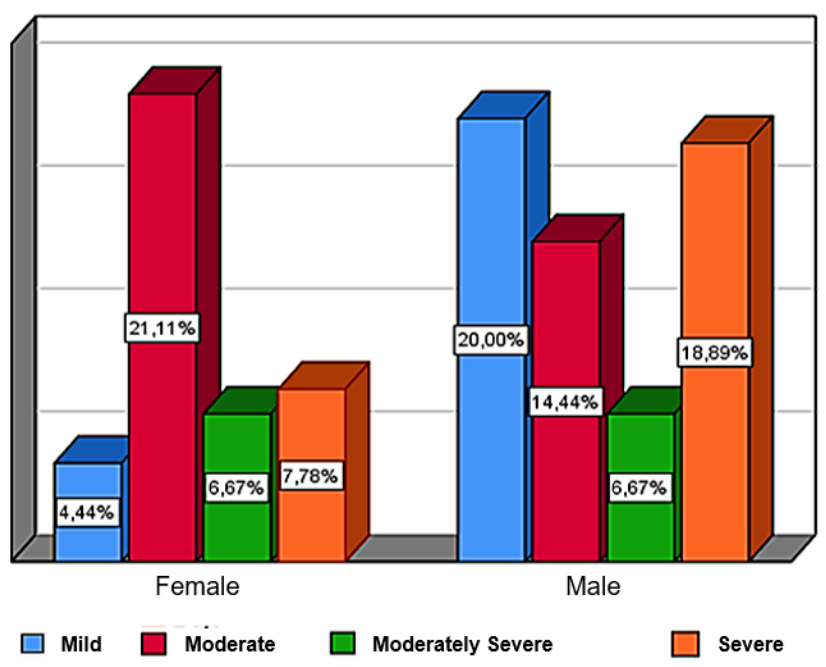

Fig. 4. Level of Depression in Patients with Tuberculosis According to Gender.

Regarding the male, the level of low depression predominated with $20.00 \%$, followed by severe depression with $18.89 \%$, while moderate depression is present in $14.44 \%$ of the population and a $6.67 \%$ present a moderately severe level.

The instrument also allowed to synthesize the signs and symptoms most present in patients with Tuberculosis. Fig. 5 shows that almost every day, $48.9 \%$ of participants show little interest or pleasure in doing things, while more than half of the days, 37.8\% have felt sad and depressed, in addition to several days, $70 \%$ have little or excessive appetite, $62.2 \%$ have had trouble sleeping, staying awake or sleeping too much, $47.8 \%$ feel tired or have little energy, $44.4 \%$ move or talk so slowly that other people may notice or are so restless and uneasy that they go from one place to another more than usual, the $42.2 \%$ have had trouble concentrating on activities such as reading the newspaper or watching television, finally $38.9 \%$ have never felt bad about themselves or that they are a failure or that they failed family and themselves, $54.4 \%$ has never thought that would be better dead or wished to harm itself in any way to.

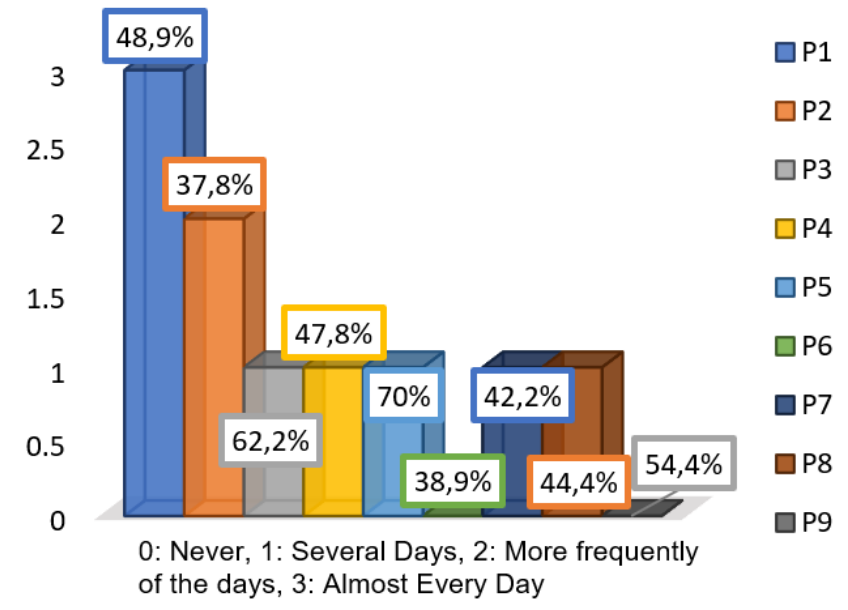

Fig. 5. Signs and Symptoms of the Level of Depression in Patients with Tuberculosis. 
The consideration of the results of our study lies in the evidence of the vulnerability of patients due to Tuberculosis, since it generates drastic changes in their lifestyle, and they tend to develop signs and symptoms that expose them to depression, which influences negatively often in other diseases (3), which can trigger in different situations, ranging from problems such as lack of adherence to treatment to suicide, which has been demonstrated in different studies such as depression and adherence in people affected with tuberculosis of the authors Llanos-Tejada and Ponce-Chang, our study is socialized, it will allow the corresponding professionals to have the opportunity to elaborate and apply plans for the prevention of the development of depression, since evidently all patients have some level of depression.

\section{DisCUSSION}

The present research work had 90 participants who had a medical diagnosis of Tuberculosis, who were receiving treatment at a health center in Los Olivos district.

The study confirms that patients with Tuberculosis tend to have different degrees or levels of depression, since as a result it was found that $100 \%$ of the participants have some level of depression according to the Patient Health Questionnaire 9, which is higher than the results, obtained in Peru from Bonilla (17), who reported that $54.5 \%$ of the study population had some level of depression, and also higher than that reported in Ethiopia by the Mayston study (18), which the prevalence of probable depression was $54.0 \%$.

The level of moderate depression prevailed in patients with $35.56 \%$, which disagrees with the results of a study carried out in Cameroon (19), where $38.9 \%$ of patients did not have depression, $36.6 \%$ had mild depression and $24.5 \%$ had moderate depression.

The level of moderate depression prevailed in patients with $35.56 \%$, which disagrees with the results of a study carried out in Cameroon (19), where $38.9 \%$ of patients did not have depression, 97 (36.6\%) had mild depression and 65 (24.5\%) had moderate depression.

The predominant sex in our research is male with $60 \%$, which coincides with the report of the Ministerio de Salud (4), where it indicates that Tuberculosis is more frequent in the male population.

Severe depression was present in $26.67 \%$ of the participants, of which $18.89 \%$ belonged to the male sex, while $7.76 \%$ to the female sex, differing with a study (19), where it was found Severe depression in $27.9 \%$ of female participants and $13.6 \%$ of male participants, in another study carried out in Pakistan (5), found that the odds of depression in women were higher than in men, which does not coincide with our study.

The instrument used allowed us to show that: almost every day, $48.9 \%$ of patients show little interest or pleasure in doing things, which is similar to the study carried out by Ambaw (18), furthermore, this symptom was related with the results of a study (4), where patients with tuberculosis and depression tend to abandon or miss their treatment for tuberculosis.
Due to the scarcity and age of studies reflecting the level of depression and its predominant symptoms and signs in patients with tuberculosis, a broader discussion could not be conducted.

\section{CONCLUSIONS}

The research was carried out using a standardized questionnaire that evaluates the level of depression (PHQ-9), consisting of 9 items, this was applied to patients with tuberculosis from the Los Olivos Lima health centers - Peru, there were a total of 90 patients who participated in the study, those who met the inclusion criteria and voluntarily wanted to participate in the study.

In addition, the health centers provided us with accessibility for the acquisition of the information collected through the instrument applied to patients with tuberculosis, for which it was necessary to present the authorization of the DIRIS Lima Norte.

Patients receiving treatment for Tuberculosis in the different Health Centers in Los Olivos present some level of depression, with the level of moderate depression prevailing in $35.56 \%$ of the population.

Moderate depression was mostly present in female patients, however, in male patients it was evident that severe depression was significant.

According to the applied instrument, the signs and symptoms of depression most present in the Tuberculosis patients evaluated were: Little interest or pleasure in doing things, showing a risk of abandoning treatment, another relevant sign was feeling sad and depressed.

It is important to highlight and encourage the use of the PHQ9 instrument, as it is an easy and quick questionnaire to administer and analyze, in addition to being valid for the timely diagnosis of depression in patients with Tuberculosis.

Finally, we consider that depression must be evaluated in all tuberculosis treatment centers, health professionals must provide adequate treatment and psychological support.

REFERENCES

[1] Yang J, Zhang M, Ahn H, Zhang Q, Jin TB, Li I, et al. Development and evaluation of a multimodal marker of major depressive disorder. Hum Brain Mapp [Internet]. 2018;39(11):4420-39. Available from: https://www.ncbi.nlm.nih.gov/pmc/articles/PMC6815672/pdf/HBM-394420.pdf

[2] Organización Mundial de la Salud. Depresión y otros trastornos mentales comunes [Internet]. Washington, D.C; 2017. 1-24 p. Available from:

https://iris.paho.org/bitstream/handle/10665.2/34006/PAHONMH17005 -spa.pdf?sequence $=1$ \&isAllowed $=y$

[3] Plan de acción sobre salud mental 2013-2020 [Internet]. Ginebra: Organización mundial de Salud; 2013. Available from: http://apps.who.int/iris/bitstream/10665/97488/1/9789243506029_spa.p df

[4] Llanos-Tejada F, Ponce-Chang C. Depresión y adherencia en personas afectadas con tuberculosis. Una exploración preliminar de datos. Rev Neuropsiquiatr [Internet]. 2019;82(2):104-9. Available from: http://www.scielo.org.pe/pdf/rnp/v82n2/a02v82n2.pdf

[5] Walker IF, Khan AM, Khan AM, Khan NM, Ayub RM, Ghias KN, et al. Depression among multidrug-resistant tuberculosis patients in Punjab, Pakistan: A large cross-sectional study. Int J Tuberc Lung Dis [Internet]. 
2018;22(7):773-8. Available from: https://pubmed.ncbi.nlm.nih.gov/ 29914603/?from_term=PHQ9+TUBERCULOSIS\&from_pos=2

[6] Mendez Fleitas L, Carmona Denis Y, Escalona Robaina C, Moreno Peña L, Ortega Peñate J. Comportamiento epidemiológico de la tuberculosis. Rev Médica Electrónica [Internet]. 2018;40(2):335-45. Available from: http://scielo.sld.cu/scielo.php?script=sci_arttext\&pid=S168418242018000200010

[7] Global Tuberculosis report 2019 [Internet]. Geneva: World Health Organization; 2019. 1-283 p. Available from: https://apps.who.int/ iris/bitstream/handle/10665/329368/9789241565714-eng.pdf?ua=1

[8] Gong W, Liang Y, Wu X. The current status, challenges, and future developments of new tuberculosis vaccines. Hum Vaccines Immunother. 2018;14(7):1697-716.

[9] Miranda Flores AF. Características clínicas y epidemiológicas de las gestantes con tuberculosis en el Instituto Nacional Materno Perinatal. Acta Medica Peru [Internet]. 2016;32(3):140. Available from: http://www.scielo.org.pe/pdf/amp/v32n3/a02v32n3.pdf

[10] Beltrán-león M, Pérez-llanos F, Sánchez L, Parra-lópez C, Navarrete M, Sánchez R, et al. Prevalencia y factores asociados a la tuberculosis y las micobacteriosis en pacientes positivos para VIH en Bogotá. Biomedica [Internet]. 2018;38(7):120. Available from: http://www.scielo.org.co /pdf/bio/v38n1/0120-4157-bio-38-01-00120.pdf

[11] Marrero Rodriguez H, Quintero Salcedo S. Factores de riesgo de la tuberculosis pulmonar en pacientes timorenses. Medisan [Internet]. 2018;22(1):57-64. Available from: http://www.medisan.sld.cu/index .php/san/article/view/1707/pdf

[12] Churchyard G, Kim P, Shah S, Rustomjee R, Gandhi N, Mathema B, et al. What We Know about Tuberculosis Transmission: An Overview. J Infect Dis [Internet]. 2017;216(Suppl 6):S629-35. Available from: https:/www.ncbi.nlm.nih.gov/pmc/articles/PMC5791742/pdf/jix362.pdf

[13] Mathema B, Andrews JR, Cohen T, Borgdorff MW, Behr M, Glynn JR, et al. Drivers of Tuberculosis transmission. J Infect Dis [Internet]. 2017;216(Suppl 6):S644-53. Available from: https://www.ncbi.nlm.nih. gov/pmc/articles/PMC5853844/pdf/jix354.pdf

[14] Alarcón V, Alarcón E, Figueroa C, Mendoza-Ticona A. Tuberculosis en el Perú: Situación epidemiológica, avances y desafíos para su control. Rev Peru Med Exp Salud Publica [Internet]. 2017;34(2):299-310. Available from: https://pubmed.ncbi.nlm.nih.gov/29177392/

[15] Giraldo Gallego N, Valencia Acevedo D, Cardona-Arias JA. Calidad de vida relacionada con la salud en tuberculosis: Revisión sistemática y metanálisis. Infectio [Internet]. 2018;22(3):124. Available from: http://www.scielo.org.co/pdf/inf/v22n3/0123-9392-inf-22-03-00124.pdf

[16] Enfermedades no transmisibles y transmisibles [Internet]. Vol. 1. Lima: Instituto Nacional de Estadística e Informática; 2018. Available from:
https://www.inei.gob.pe/media/MenuRecursivo/publicaciones_digitales/ Est/Lib1526/libro.pdf

[17] Bonilla Asalde CA, Rivera Lozada IC, Rivera Lozada O. Depresión en pacientes con Tuberculosis en una región del Perú: Un estudio transversal. Rev invetigación la Univ Norber Wiener [Internet]. 2019;8:43-51. Available from: https://revistadeinvestigacion.uwiener. edu.pe/ojs/index.php/revistauwiener/article/view/42/20

[18] Ambaw F, Mayston R, Hanlon C, Alem A. Burden and presentation of depression among newly diagnosed individuals with TB in primary care settings in Ethiopia. BMC Psychiatry [Internet]. 2017;17(57):1-10. Available from: https:/www.ncbi.nlm.nih.gov/pmc/articles/ PMC5297050/pdf/12888_2017_Article_1231.pdf

[19] Kehbila J, Jabea Ekabe C, Ndemnge Aminde L, Jacques N. Noubiap J, Nde Fon P, Lobe Monekosso G. Prevalence and correlates of depressive symptoms in adult patients with pulmonary tuberculosis in the Southwest Region of Cameroon. Infect Dis Poverty [Internet]. 2016;5(1):1-8. Available from: https://www.ncbi.nlm.nih.gov/pmc/ articles/PMC4895984/pdf/40249_2016_Article_145.pdf

[20] Park SC, Lee HY, Lee DW, Hahn SW, Park SH, Kim YJ, et al. Screening for depressive disorder in elderly patients with chronic physical diseases using the patient health questionnaire-9. Psychiatry Investig. 2017;14(3):306-13.

[21] De Castro-Silva KM, Carvalho AC, Cavalcanti MT, Da Martins PS, França JR, Oquendo M, et al. Prevalence of depression among patients with presumptive pulmonary tuberculosis in Rio de Janeiro, Brazil. Brazilian J Psychiatry [Internet]. 2019;41(4):316-23. Available from: https://www.scielo.br/scielo.php?script=sci_arttext\&pid=S151644462019000400316

[22] Udedi M, Muula AS, Stewart RC, Pence BW. The validity of the patient health Questionnaire-9 to screen for depression in patients with type-2 diabetes mellitus in non-communicable diseases clinics in Malawi. BMC Psychiatry [Internet]. 2019;19(1):1-7. Available from: https://www.ncbi .nlm.nih.gov/pmc/articles/PMC6391834/

[23] Su N, Yu K, Ye Y, Chen S. The validity study of Patient Health Questionnaire-9 items for Internet screening in depression among Chinese University students. Physiol Behav [Internet]. 2016;176(1):100-106. Available from: https:/www.ncbi.nlm.nih.gov/ pmc/articles/PMC6391834/

[24] Villarreal-Zegarra D, Copez-Lonzoy A, Bernabé-Ortiz A, MelendezTorres GJ, Bazo-Alvarez JC. Valid group comparisons can be made with the Patient Health Questionnaire (PHQ-9): A measurement invariance study across groups by demographic characteristics. PLoS One [Internet]. 2019;14(9):1-15. Available from: https://journals.plos. org/plosone/article?id=10.1371/journal.pone.0221717 